\title{
Factors associated with unintended pregnancy among women attending antenatal care in Maichew Town, Northern Ethiopia, 2017
}

\author{
Eskeziaw Abebe Kassahun ${ }^{1 *}$, Liknaw Bewket Zeleke², Amanuel Addisu Dessie 3 , Bisrat Gebrehiwot Gersa ${ }^{4}$, \\ Hayat Ibrahim Oumer ${ }^{5}$, Hunegnaw Alemaw Derseh ${ }^{6}$, Mulugeta Wodaje Arage ${ }^{1}$ and Getnet Gedefaw Azeze ${ }^{1}$
}

\begin{abstract}
Objective: Unintended pregnancy is one of the most public health issues in the world, and it is the major sexual and reproductive health problem which carries a higher risk of morbidity and mortality for women, often due to unsafe abortion. Even though family planning services are effective and available than ever before, unintended pregnancy and unsafe abortion are the major public health problems in the study area. Therefore, this study aimed at assessing the magnitude and associated factors of unintended pregnancy among pregnant women attending antenatal care follow up in Maichew town, northern Ethiopia. An institution based cross-sectional study was conducted on 329 pregnant women selected with a systematic sampling technique from April 5 to May 4, 2017.

Result: The magnitude of unintended pregnancy among pregnant women attending antenatal care in Maichew was found to be $29.7 \%$ ( $95 \% \mathrm{Cl} 24.30,35.50)$. On the other hand, single in marital status ( $\mathrm{AOR}=38.6,95 \% \mathrm{Cl} 10.07,148.01$ ), living alone $(A O R=9.9,95 \% \mathrm{Cl} 1.80,53.40)$ and having three or four children $(A O R=3.5,95 \% \mathrm{Cl} 1.10,11.04)$ were factors associated with an unintended pregnancy. Creating awareness about unintended pregnancy associated factors and implication of unintended pregnancy is highly recommended.
\end{abstract}

Keywords: Unintended pregnancy, Pregnant women, Maichew, Ethiopia

\section{Introduction}

Unintended pregnancies are pregnancies that are unwanted which occurs with no desire to have a child, mistimed which occurs before the desired time or unplanned at a time of conception [1]. Worldwide, an estimated 33 million unintended pregnancies are a result of contraceptive failure or incorrect use [2]. In developing countries, the majority of unintended pregnancy occurs due to using traditional family planning methods or not using any type of modern contraceptives [3], and it's the main reason for induced abortion [4]. In Ethiopia, 24.7 and $42 \%$ of unintended pregnancy caused by contraceptive failure and not using contraceptive methods, respectively [5].

\footnotetext{
*Correspondence: eskeziaw02@gmail.com

${ }^{1}$ Department of Midwifery, Faculty of Health Sciences, Woldia University, Woldia, Ethiopia

Full list of author information is available at the end of the article
}

Globally, each day about 100 million sexual intercourse takes place, of these 1 million conceptions occur [6]. Among 208.2 million pregnancies of the world, $41 \%$ are unintended [7]. In addition, 213 million pregnancies occur each year, $89 \%$ of this occurs in developing countries, and $40 \%$ of these are unintended pregnancies [8].

Unintended pregnancy is the major sexual and reproductive health problems that impose to substantial health, economical and psychosocial costs to individual and society as well as significant emotional distress to women, families, and society $[3,9,10]$. Besides, contributing to late antenatal care (ANC) visit, increase exposure to the substance, less care for their child, and experiencing physical and psychological violence [11]. The impact of unintended pregnancy is higher during the adolescent period that levy to dropping out of school, unstable and lack of proper management of family relationships [12]. In addition, children born to teenage mothers are much more likely to experience a range of negative outcomes 
in later life, such as developmental disabilities, behavioral issues and poor academic performance [13].

About half of unintended pregnancies in developing countries result in unsafe abortion which accounts for $13 \%$ of maternal deaths [14]. Poor educational status, lack of access to health services and health education, poor economic status, single in marital status, peer pressure, sexual violence, and family planning failure were exposed to unintended pregnancy $[9,15,16]$.

Unintended pregnancy is one of the most evident for the violation of women's sexual and reproductive rights in developing countries. Despite the availability of highly effective methods of contraception, different studies in Ethiopia revealed that there is a high level of unintended pregnancy [17-20]. Therefore, this study aimed at assessing the magnitude and associated factors of unintended pregnancy among pregnant women attending antenatal care in Maichew town, northern Ethiopia.

\section{Main text \\ Methods \\ Study design and period}

An institution based cross-sectional study was conducted from April 5 to May 4, 2017.

\section{Study area}

The study was conducted in Maichew town, Tigray region, northern Ethiopia. Maichew town is found $665 \mathrm{~km}$ far from Addis Ababa, the capital of Ethiopia. According to the Central Statistical Agency of Ethiopia (CSA, 2007), the total population of 23,395 lives in Maichew town, of which 12,395 are females. The town has one general hospital, two health centers, and five private clinics.

\section{Study population}

All pregnant women who had ANC follow up during data collection were included in the study. However, pregnant women who were seriously ill during data collection were excluded.

\section{Sample size determination and sampling procedure}

The required sample size was determined using a single population proportion formula by considering the proportion of unintended pregnancy in Welkaite, $26.4 \%$ [17], a $95 \%$ confidence interval (CI) and $5 \%$ of margin of error. By adding 10\% for the non-response rate, the final sample was 329 women. The data were collected from all governmental health institutions in Maichew town. Based on the previous 2 months of the Maichew Town Health Administrative report, 325,189 and 125 pregnant women had ANC follow up in Lemlem Karl hospital, Maichew health center and Semere Melese health center, respectively. Then, 167 women from Lemlem Karl hospital, 68 women from Maichew health center, and 97 women from Semere Melese health center were selected using systematic sampling and proportional allocation technique.

\section{Data collection tools and techniques}

A structured interviewer-administered face to face interview was used to collect data. The questionnaire was consisted of sociodemographic and economic characteristics, sexual behaviors, and behavioral characteristics of participants which was initially prepared in English and translated into local languages (Amharic and Tigrigna) and back-translated to the English language by three language experts to check the consistency. A total of three BSc. Midwifery data collectors involved in the study. Data collectors received 3 days of training prior to data collection. A pretest was done on five percent of the sample on the Garjale health center (outside the study area). Finally, the collected data were checked for its consistency and completeness in each day before compiling.

\section{Data processing and analysis}

The collected data were checked and entered into EpiData version 3.10 and exported into SPSS version 20 statistical software for analysis. Descriptive statistics were carried out and the result was presented in text and table. Bivariate logistic regression analysis was used to identify factors associated with an unintended pregnancy. Crude odds ratio (COR) and adjusted odds ratio (AOR) with 95\% confidence interval (CI) was calculated to identify factors associated with unintended pregnancy. Variables with a p-value less than 0.2 in the bivariable logistic regression analysis were retained into a multivariable logistic regression analysis to control the potential confounders. In the multivariable logistic regression analysis, variables with p-value $<0.05$ at $95 \%$ confidence interval were considered as statistically significant.

\section{Result}

\section{Socio-demographic and economic characteristics}

A total of 313 pregnant women participated in the study making the response rate $95.14 \%$. The median age of the respondents was 26 years with an inter-quartile range (IQR) of 8 years. The majority $(78.3 \%)$ of women were in the age range of $18-34$ years. Nearly two-thirds $(68.1 \%)$ of women lived in an urban area. Moreover, 33.1, 11.8 and $8 \%$ of women had no formal education, lived alone and had five or more children, respectively (Table 1). 
Table 1 Socio-demographic and economic characteristics of pregnant women attending antenatal care in Maichew town, northern Ethiopia, $2017(n=313)$

\begin{tabular}{|c|c|c|}
\hline Variables & Frequency & Percentage \\
\hline \multicolumn{3}{|l|}{ Residence } \\
\hline Urban & 213 & 68.0 \\
\hline Rural & 100 & 32.0 \\
\hline \multicolumn{3}{|l|}{ Marital status } \\
\hline Married & 245 & 78.3 \\
\hline Single & 68 & 21.7 \\
\hline \multicolumn{3}{|l|}{ Age (years) } \\
\hline$<18$ & 14 & 4.5 \\
\hline $18-34$ & 260 & 83.1 \\
\hline$>35$ & 39 & 12.5 \\
\hline \multicolumn{3}{|l|}{ Mother's education } \\
\hline No formal schooling & 97 & 31.0 \\
\hline Primary school & 46 & 14.7 \\
\hline Secondary school & 93 & 29.7 \\
\hline College or university & 77 & 24.6 \\
\hline \multicolumn{3}{|l|}{ Mather's occupation } \\
\hline Student & 56 & 17.9 \\
\hline Daily laborer or unemployed & 37 & 11.8 \\
\hline Farmer & 34 & 10.9 \\
\hline Civil servant & 57 & 18.2 \\
\hline Merchant & 27 & 8.6 \\
\hline Housewife & 102 & 32.6 \\
\hline \multicolumn{3}{|l|}{ Husband's education } \\
\hline No formal education & 102 & 32.6 \\
\hline Primary school & 50 & 16.0 \\
\hline Secondary school & 66 & 21.1 \\
\hline College or university & 95 & 30.4 \\
\hline \multicolumn{3}{|l|}{ Husband's occupation } \\
\hline Student & 34 & 10.9 \\
\hline Daily laborer or unemployed & 28 & 8.5 \\
\hline Farmer & 96 & 30.7 \\
\hline Civil servant & 65 & 20.8 \\
\hline Merchant & 90 & 28.8 \\
\hline \multicolumn{3}{|l|}{ Lived with } \\
\hline Husband & 214 & 68.4 \\
\hline Parents & 62 & 19.8 \\
\hline Alone & 37 & 11.8 \\
\hline \multicolumn{3}{|l|}{ Economic status } \\
\hline Poor & 159 & 51.0 \\
\hline Medium & 107 & 34.0 \\
\hline Rich & 47 & 15.0 \\
\hline \multicolumn{3}{|l|}{ No children } \\
\hline $0-2$ & 212 & 68.0 \\
\hline $3-4$ & 76 & 24.0 \\
\hline$\geq 5$ & 25 & 8.0 \\
\hline \multicolumn{3}{|l|}{ HIV status } \\
\hline Negative & 298 & 95.2 \\
\hline Positive & 10 & 3.2 \\
\hline Unknown & 5 & 1.6 \\
\hline
\end{tabular}

\section{Sexual and behavioral characteristics}

About, $18.8 \%$ of women had multiple sexual partners. A substantial proportion of women (78\%) discussed with their partner on pregnancy-related issues. The most (93.3\%) and 53\% of women heard about and reported that school was a major source of information on contraceptive methods, respectively. Nearly one-third $(65.8 \%)$ of the participants had good knowledge of contraceptive methods (Table 2).

\section{Prevalence of unintended pregnancy 93012}

The overall prevalence of unintended pregnancy was $29.7 \%$ (95\% CI 24.30, 35.50).

\section{Factors associated with unintended pregnancy}

Both bivariable and multivariable logistic regression analyses were done to see the effects of the selected characteristics on unintended pregnancy. As it is presented in Table 3, knowledge of family planning, economic status, participant's age, living arrangements, number of children, mother's occupation, husband's occupation, and marital status were factors associated with an unintended pregnancy in the bivariable analysis.

Moreover, the result of multivariable logistic regression analysis revealed that marital status, number of children and living arrangement were significantly associated with unintended pregnancy. In this study, the high odds of unintended pregnancy were observed among women who lived alone $(\mathrm{AOR}=9.9,95 \% \mathrm{CI}$ $1.80,53.40)$ and had three or four children $(\mathrm{AOR}=3.5$, $95 \%$ CI 1.10, 11.04). Moreover, the odds of unintended pregnancy were 38.6 times $(\mathrm{AOR}=38.6,95 \% \mathrm{CI} 10.07$, 148.01 ) as high among women who were single compared to married (Table 3 ).

\section{Discussion}

This study was conducted to assess the prevalence and associated factors of unintended pregnancy among women attending antenatal care in Maichew town, northern Ethiopia.

The prevalence of unintended pregnancy among women attending ANC in Maichew town was found to be $29.7 \%$ (95\% CI $24.3 \%, 35.5 \%$ ). The finding is in line with other studies done in Hosanna (34\%) [21], Walkait (26\%) [22] and Mekelle town (28.6\%) [23]. But compared to other studies, this finding is lower than those of studies done in Addis Ababa (37\%) [3], Kenya (41\%) [24], and Wolaita zone (36.6\%) [25]. The possible reason for the difference might be due to the socio-demographic difference of participants, 
Table 2 Sexual and behavioral characteristics of study participants in Maichew town, northern Ethiopia, 2017 $(\mathrm{n}=313)$

\begin{tabular}{|c|c|c|}
\hline Category & Frequency & Percentage \\
\hline \multicolumn{3}{|c|}{ Number of sexual partners } \\
\hline One & 254 & 81.2 \\
\hline Two and more & 59 & 18.8 \\
\hline \multicolumn{3}{|c|}{ Communicate with partner on pregnancy } \\
\hline Yes & 244 & 78.0 \\
\hline No & 69 & 22.0 \\
\hline \multicolumn{3}{|c|}{ Heard about family planning } \\
\hline Yes & 292 & 93.3 \\
\hline No & 21 & 6.7 \\
\hline \multicolumn{3}{|c|}{ Source of information on family planning $(n=292)$} \\
\hline Family & 50 & 17.1 \\
\hline Friend & 121 & 41.4 \\
\hline School & 155 & 53.1 \\
\hline Religious institution & 13 & 4.5 \\
\hline Media & 98 & 33.6 \\
\hline Health institution & 117 & 40.1 \\
\hline \multicolumn{3}{|c|}{ Awareness of contraceptive methods } \\
\hline Pills & 255 & 87.3 \\
\hline Condom & 171 & 58.6 \\
\hline Injectable & 262 & 89.7 \\
\hline IUCD & 183 & 62.7 \\
\hline Implant & 92 & 31.5 \\
\hline Female sterilization & 39 & 13.4 \\
\hline Male sterilization & 33 & 11.3 \\
\hline \multicolumn{3}{|c|}{ Ever used family planning } \\
\hline Yes & 238 & 76.0 \\
\hline No & 75 & 24.0 \\
\hline \multicolumn{3}{|l|}{ Used family planning ${ }^{a}$} \\
\hline Pill & 117 & 49.2 \\
\hline Condom & 36 & 15.1 \\
\hline Injectable & 165 & 69.3 \\
\hline IUCD & 2 & 0.8 \\
\hline Implant & 41 & 17.2 \\
\hline \multicolumn{3}{|c|}{ Knowledge of family planning } \\
\hline Good & 206 & 65.8 \\
\hline Poor & 107 & 34.2 \\
\hline
\end{tabular}

aultiple response

particularly the aforementioned studies were conducted in capital cities whereas the current study was conducted in district town having poor awareness of family planning, and sexual and reproductive health rights. Moreover, the prevalence of this study is higher than those of other findings in Arbaminch town (19.4\%) [26], South Africa (21.6\%) [27] and India (22.2\%) [21]. This might be due to the difference in the educational status of the participants having more awareness of family planning methods. The difference in the availability and accessibility of family planning methods may contribute to the difference.

Pregnant women who were single and living alone were independently associated with an unintended pregnancy. Single women were more likely to develop untended pregnancy than a married one. This study is supported by studies done in Gelemso [9], Wolaita zone [25], Mulago hospital [28], Ghana [29] and Kenya [24]. This might be due to women who are single or living alone are prone to unsafe sexual acts because of parents or families are important to monitor and support the behavior, and sexual and reproductive health of women. Moreover, it might be due to social influence or bad taboos that prevent women to use family planning methods.

In this study, women who had three or more children were more likely to develop unintended pregnancy as compared to their counterpart. The same finding was observed in Felegehiwote, Bahir Dar [30], Gelemso [31], Hosanna town [21], rural Ghana [29] and Zambia [32] studies. This might be due to women having a large family size (children) spend time to take care of their children which may result in missing appointments and even delay to seek maternal health services.

\section{Conclusion}

The prevalence of unintended pregnancy was higher in the study area which confirmed the major public health problem. Marital status, the number of children and living arrangement were significantly associated with an unintended pregnancy. Hence, creating awareness on sexual and reproductive health rights, increasing the accessibility of maternal health services for women are recommended to reduce unintended pregnancy.

\section{Limitation of the study}

The major limitation of this study was the use of small study participants. It's recommended to use a large sample size for future studies.

\section{Abbreviations}

ANC: antenatal care; AOR: adjusted odds ratio; CSA: Central Statistics Agency; $\mathrm{Cl}$ : confidence interval; COR: crude odds ratio; EDHS: Ethiopian Demographic 
Table 3 Bivariate and multivariable logistic regression analyses of unintended pregnancy among pregnant women attending antenatal care in Maichew town, northern Ethiopia, 2017

\begin{tabular}{|c|c|c|c|c|}
\hline \multirow[t]{2}{*}{ Category } & \multicolumn{2}{|c|}{ Unintended pregnancy } & \multirow[t]{2}{*}{ COR $(95 \% \mathrm{Cl})$} & \multirow[t]{2}{*}{ AOR $(95 \% \mathrm{Cl})$} \\
\hline & Yes & No & & \\
\hline \multicolumn{5}{|c|}{ Knowledge of contraceptive methods } \\
\hline Poor & 46 & 61 & $2.6(1.68,4.50)$ & $1.3(0.25,6.70)$ \\
\hline Good & 47 & 159 & 1.0 & 1.0 \\
\hline \multicolumn{5}{|l|}{ Economic status } \\
\hline Poor & 66 & 93 & $4.8(1.94,12.0)$ & $3.5(0.60,18.90)$ \\
\hline Medium & 21 & 86 & $1.7(0.62,4.44)$ & $2.3(0.40,10.60)$ \\
\hline Rich & 6 & 41 & 1.0 & 1.0 \\
\hline \multicolumn{5}{|l|}{ Age of participant (years) } \\
\hline$<18$ & 11 & 3 & 1.0 & 1.0 \\
\hline $18-34$ & 64 & 196 & $0.09(0.24,0.32)$ & $1.0(0.09,11.70)$ \\
\hline$>35$ & 21 & 18 & $0.23(0.06,0.90)$ & $5.6(0.30,83.50)$ \\
\hline \multicolumn{5}{|l|}{ Lived with } \\
\hline Husband & 29 & 185 & 1.0 & 1.0 \\
\hline Parents & 33 & 29 & $7.3(3.80,13.60)$ & $2.3(0.70,6.90)$ \\
\hline Alone & 31 & 6 & $32.8(12.60,85.80)$ & $9.9(1.80-53.40)^{*}$ \\
\hline \multicolumn{5}{|l|}{ Number of children } \\
\hline $0-2$ & 62 & 150 & 1.0 & 1.0 \\
\hline $3-4$ & 20 & 56 & $0.9(0.47,1.55)$ & $3.5(1.10,11.04)^{*}$ \\
\hline$>5$ & 11 & 14 & $1.9(0.81,4.41)$ & $2.6(0.50,13.10)$ \\
\hline \multicolumn{5}{|l|}{ Mother's occupation } \\
\hline Student & 21 & 81 & 1.0 & 1.0 \\
\hline House wife & 34 & 22 & $6.0(2.9,12.24)$ & $0.5(0.08,3.80)$ \\
\hline Daily labor or unemployed & 17 & 15 & $3.7(1.63,8.16)$ & $1.7(0.22,13.40)$ \\
\hline Peasant & 8 & 26 & $1.2(0.47,2.99)$ & $1.05(0.11,10.10)$ \\
\hline Civil servant & 6 & 51 & $0.45(0.17,1.2)$ & $0.2(0.02,2.28)$ \\
\hline Merchant & 6 & 21 & $1.1(0.39,3.07)$ & $1.05(0.10,8.10)$ \\
\hline \multicolumn{5}{|l|}{ Husband's occupation } \\
\hline Peasant & 33 & 63 & 1.0 & 1.0 \\
\hline Student & 12 & 22 & $2.4(1.22,4.8)$ & $1.3(0.35,4.80)$ \\
\hline Daily laborer or unemployed & 7 & 21 & $8.5(3.49,20.5)$ & $1.1(0.20,6.20)$ \\
\hline Civil servant & 15 & 50 & $1.5(0.50,4.20)$ & $1.3(0.23,6.60)$ \\
\hline Merchant & 16 & 74 & $1.3(0.60,3.10)$ & $4.4(0.10,17.50)$ \\
\hline \multicolumn{5}{|l|}{ Marital status } \\
\hline Married & 33 & 212 & 1.0 & 1.0 \\
\hline Single & 60 & 8 & $48.1(21-109.8)$ & $38.6(10.07,148.01)^{*}$ \\
\hline
\end{tabular}

*Significantly associated factors at $p$-value less than 0.05

and Health Survey; IQR: inter quartile range; SPSS: Statistical Package for Social Sciences.

\section{Acknowledgements}

The authors would like to thank participants for their willingness to participate and provided us the valuable data. We are very grateful to Woldia University and Maichew zonal health offices for their supports.

\section{Authors' contributions}

EAK, BGG and HIO developed the concept of the research, acquired the research proposal, facilitated data collection and data entry. EAK and LBZ were prepared the first daft of this manuscript. EAK, BGG, HIO, LBZ, ADD, HAD, MWA and GGA participated in statistical analyses and critically reviewed the manuscript. All authors read and approved the final manuscript.

\section{Funding}

No specific fund was secured for this study

Availability of data and materials

Data supporting this finding can be found in the manuscript. All the data sets supporting the paper are available from the corresponding author on reasonable request. 


\section{Ethics approval and consent to participate}

Ethical clearance was obtained from Woldia University, Faculty of Health Sciences. A supportive letter was also obtained from Zonal Health Offices. Detail explanation about the objective and benefit of the study was explained to the participants to ensure their full cooperation. Written consent was obtained from the partner or legal guardians for those women aged less than 18 years. Besides assent was secured from participants aged below 18 years. Those who were aged 18 years and above, provided by written consent on their own. Confidentiality was maintained by keeping anonymously of any personal identifiers.

\section{Consent for publication}

Not applicable.

\section{Competing interests}

The authors declare that they have no competing interests.

\section{Author details}

${ }^{1}$ Department of Midwifery, Faculty of Health Sciences, Woldia University, Woldia, Ethiopia. ${ }^{2}$ College of Medicine and Health Sciences, Debre Markos University, Debre Markos, Ethiopia. ${ }^{3}$ Department of Public Health, Faculty of Health Sciences, Woldia University, Woldia, Ethiopia. ${ }^{4}$ Minilik Hospital, Addis Ababa, Ethiopia. ${ }^{5}$ Eman Herbal Center, Addis Ababa, Ethiopia. ${ }^{6}$ Department of Nutrition, College of Medicine and Health Sciences, Bahir Dar University, Bahir Dar, Ethiopia.

Received: 13 February 2019 Accepted: 29 June 2019

Published online: 05 July 2019

\section{References}

1. Askew I. Causes and consequences of unintended pregnancy in developing countries. New York: Population Council; 2011.

2. World Health Organization (WHO). Unsafe abortion-global and regional estimates of the incidence of unsafe abortion and associated mortality in 2008. 6th ed. Geneva: World Health Organization; 2011.

3. Mulatu T. Prevalence of unwanted pregnancy and associated factors among women in reproductive age groups at selected health facilities in Addis Ababa city, Ethiopia; 2014.

4. Brown SS, Eisenberg L. The best intention: unintended pregnancy and the well being of children and families. Washington, D.C: National Academies Press; 1999.

5. Getu Melese K, Gebrie MH, Berta Badi M, Fekadu Mersha W. Unintended pregnancy in Ethiopia: community based cross-sectional study. Obst Gynecol Int. 2016;2016:4374791.

6. World Health Organization (WHO). Engaging men in changing gender based inequality in health: evidence from programme intervention. Geneva: World Health Organization; 2007.

7. Singh S, Sedgh G, Hussain R. Unintended pregnancy: worldwide levels, trends, and outcomes. Stud Fam Plan. 2010;41(4):241-50.

8. Singh $\mathrm{S}$, Sedgh $\mathrm{G}$, Hussain R, Eilers M. Incidence of unintended pregnancies worldwide in 2012 and trends since 1995: 2012.

9. Mamboleo N. Unwanted pregnancy and induced abortion among female youths: a case study of Temeke district. Muhimbili University of Health and Allied Sciences; 2012.

10. Hernandez ND. Exploration of the meaning and consequences of unintended pregnancy among latina cultural subgroups; 2013.

11. Logan C, Holcombe E, Manlove J, Ryan S. The consequences of unintended childbearing: a white paper. Washington, D.C: Child Trends and The National Campaign to Prevent Teen and Unplanned Pregnancy; 2007.

12. World Health Organization (WHO). Adolescent pregnancy. Geneva: World Health Organization; 2013

13. Hofferth SL. Early childbearing and children's achievement and behavior over time. Perspect Sex Reprod Health. 2002;34(1):41-9.
14. World Health organization (WHO). Why do many women's still die in pregnancy or child birth. Geneva: World Health organization; 2013.

15. Bahk J, Yun SC, Kim YM, Khang YH. Impact of unintended pregnancy on maternal mental health a casual analysis using follow up date of the panel study on Korean children. BMC Pregnancy Child Bear. 2015;15:85.

16. Contraception ST. The global epidemic of unintended pregnancies. 1990-2015.

17. Central Statistical Agency [Ethiopia], ICF International. Ethiopia demographic and health survey 2011. Central Statistical Agency and ICF International: Addis Ababa, Ethiopia and Calverton, Maryland, USA; 2012.

18. Yenealem F, Niberet G. Prevalence and associated factors of unintended pregnancy among pregnant woman in Gondar town, North west Ethiopia. BMC Res Notes. 2014;12:161.

19. Gizaw W, Fetene G, Mohammed S, Alemu A. Magnitude of unplanned pregnancy and its associated factors among pregnant women attending antenatal care at Tepi General Hospital Sheka Zone, Southwest Ethiopia, 2017. Insights Reprod Med. 2018;2(2):1.

20. Goshu YA, Yitayew AE. Prevalence and determinant factors of unintended pregnancy among pregnant women attending antenatal clinics of Addis Zemen hospital. PLoS One. 2019;14(1):e0210206.

21. Hamdela B, Tilahun T. Unwanted pregnancy and associated factors among pregnant married women in Hosanna Town, Southern Ethiopia. PLoS One. 2012;7(6):e39074

22. Abayu H, Birhanu Z, Nega A, Kidanemariam A. Prevalence and associated factors of unintended pregnancy in Welkaite Woreda, Tigray and North Ethiopia cross sectional study. J Pregnancy Child Health. 2015;7:137

23. Weldegebreal R, Melaku YA, Alemayehu M, Gebrehiwot TG. Unintended pregnancy among female sex workers in Mekelle city, northern Ethiopia: a cross-sectional study. BMC Public Health. 2015;15(1):40.

24. Beguy D, Mumah J, Gottschalk L. Unintended pregnancies among young women living in urban slums: evidence from a prospective study in Nairobi City, Kenya. PLoS One. 2014;9(7):e101034.

25. Getachew FD. Level of unintended pregnancy and its associated factors among currently pregnant women in Duguna Fango District, Wolaita Zone, Southern Ethiopia. Malays J Med Biol Res. 2015;2(2):75-88.

26. Gite A, Liulseged N, Seyife H, Abrha Y, Workineh Y, Shegaze M. Unintended pregnancy: magnitude and associated factors among pregnant women in Arba Minch Town, Gamo Gofa Zone, Ethiopia, 2015. Reprod Syst Sex Disord. 2016;5(193):1-6.

27. Schwartz SR, Rees H, Mehta S, Venter WD, Taha TE, Black V. High incidence of unplanned pregnancy after antiretroviral therapy initiation: findings from a prospective cohort study in South Africa. PLoS One. 2012;7(4):e36039.

28. Peter I. The prevalence, associated factors and coping strategies of women with unintended pregnancies attending antenatal care in Mulago hospital Makerere university college of health sciences; 2012.

29. Eliason S, Baiden F, Yankey BA, Awusabo-Asare K. Determinants of unintended pregnancies in rural Ghana. BMC Pregnancy Childbirth. 2014; $14: 261$.

30. Wang H, Long L, Cai H, Wu Y, Xu J, Shu C, Wang P, Li B, Wei Q, Shang X, Wang $X$. Contraception and unintended pregnancy among unmarried female university students: a cross-sectional study from China. PLoS One. 2015;10(6):e0130212.

31. Mohammed F, Musa A, Amano A. Prevalence and determinants of unintended pregnancy among pregnant woman attending ANC at Gelemso General Hospital, Oromiya Region, East Ethiopia: a facility based crosssectional study. BMC Women's Health. 2016;16:56.

32. Wall KM, Haddad L, Vwalika B, Khu NH, Brill I, Kilembe W, Stephenson R, Chomba E, Vwalika C, Tichacek A, Allen S. Unintended pregnancy among HIV positive couples receiving integrated HIV counseling, testing, and family planning services in Zambia. PLoS One. 2013;8(9):e75353.

\section{Publisher's Note}

Springer Nature remains neutral with regard to jurisdictional claims in published maps and institutional affiliations. 